\title{
GESTÃO DE RECURSOS HUMANOS EM MICRO E PEQUENAS EMPRESAS: DIRECIONAMENTOS DO SEBRAE PARA ESTIMULAR O DESENVOLVIMENTO DE POLÍTICAS E PRÁTICAS
}

\author{
HUMAN RESOURCE MANAGEMENT IN \\ MICRO AND SMALL ENTERPRISES: SEBRAE \\ DIRECTIONS TO STIMULATE THE \\ DEVELOPMENT OF POLITICS AND PRACTICES
}

Teodoro Campos Malta ${ }^{1}$ Marta Corrêa Machado ${ }^{2}$ André Luiz Fischer ${ }^{3}$

Recebido em: 22 de fevereiro de 2017 Aprovado em: 15 de maio de 2017 Sistema de Avaliação: Double Blind Review RGD | v. 14 |n. 2 |p. 111-125 | jul./dez. 2017

\begin{abstract}
RESUMO
O presente artigo tem por finalidade estudar os direcionamentos oferecidos pelo SEBRAE quanto ao desenvolvimento de políticas e práticas de Gestão de Recursos Humano (GRH) em Micro e Pequenas Empresas. O foco principal deste trabalho recai na identificação de quais aspectos das políticas e práticas de GRH estão contemplados nesses direcionamentos. Utilizou-se a metodologia de pesquisa qualitativa através do estudo de caso único, uma vez que, de acordo com a literatura sobre o tema, a entidade estudada apresenta características de raridade que justificam essa opção. As fontes de evidência foram entrevistas semiestruturadas, que foram trianguladas com a análise documental de informações contidas em portais regionais que o SEBRAE detém para o estado de São Paulo e para o estado do Rio Grande do Sul, além de brochuras em formato PDF constantes na biblioteca virtual da instituição. Os dados obtidos apontaram a existência de direcionamentos considerados genéricos, não apresentando um nível de profundidade que sustente a criação de políticas e práticas de GRH.
\end{abstract}

Palavras-chave: Gestão de Recursos Humanos. SEBRAE. Micro e Pequenas Empresas.

\begin{abstract}
This article aims to study the directions offered by SEBRAE to the development of policies and practices in Human Resources Management (HRM) to Micro and Small Enterprises. The focus of this work concentrates in the identification of the aspects of HRM policies and practices have been covered by these directions. We used a qualitative research approach of single case study once SEBRAE presents characteristics that justify this option. The sources of evidence used were semi structured interviews which were triangulated with analysis of information presented at the regional portals of SEBRAE for the states of Sao Paulo and Rio Grande do Sul, along with PDF brochures found in in the virtual library of the entity. Data obtained indicates the existence of directions, which, however, were considered generic and did not show a level of depth that allows the creation of policies and practices of HRM in Micro and Small Enterprises.
\end{abstract}

Keywords: Human Resource Management. SEBRAE. Micro and Small Enterprises.

\footnotetext{
Doutor em Administração (Universidade Nove de Julho/Brasil). E-mail: teodoro@ gruposerintegral.com.br.

${ }^{2}$ Doutoranda em Administração (Fundação Getúlio Vargas/Brasil). E-mail: ufscmarta@ gmail.com.

${ }^{3}$ Doutor em Administração (Universidade de São Paulo/Brasil). E-mail: afischer@usp.br.
} 


\section{INTRODUÇÃO}

A Gestão de Recursos Humanos (GRH) em Micro e Pequenas Empresas (MPE) é tema que emergiu no campo de estudos de GRH ao longo da década de noventa (DUNDON et al., 1999). Essas empresas apresentam características de flexibilidade, escassez de recursos e baixo nível de especialização técnica e gerencial de seus integrantes, enfrentando dificuldades para desenvolver políticas e práticas de GRH (WILKINSON, 1999). Autores destacam que práticas e políticas de GRH são importantes para o desenvolvimento das empresas, impactando positivamente no aumento do desempenho financeiro e organizacional (BOXALL; PURCELL, 2008).

Uma gestão de recursos humanos integrada com a estratégia organizacional possibilita identificar oportunidades para desenvolver novos mercados e encontrar soluções para problemas enfrentados nas rotinas organizacionais. Nesse sentido, as práticas de GRH devem ser compostas com as estratégias organizacionais e influenciadas pela construção coletiva, fruto da colaboração conjunta dos membros da organização (LEGGE, 2005).

No contexto das MPE, Dundon et al. (1999) explicam que a GRH pode estar associada a um ambiente familiar, amigável, no qual as informações são compartilhadas, havendo uma grande proximidade e cordialidade entre os integrantes. No entanto, este ambiente pode ser nebuloso e as relações sindicais não incentivadas, havendo assim, em um certo nível, exploração da mão de obra.

A falta de habilidade por parte dos proprietários-dirigentes para desenvolver políticas e práticas de GRH é outro aspecto complicador que interfere negativamente no crescimento de MPE. Os proprietários-dirigentes relatam dificuldades para recrutar, motivar e reter pessoas qualificadas e isso repercute na falta de conexão entre o colaborador com a estratégia da empresa (MAZZAROL, 2003).

Mambula (2002) destaca a importância de programas e serviços que provêm suporte para o desenvolvimento e aprimoramento das rotinas organizacionais em MPE. As MPE, em razão das características de escassez de recursos e baixo nível de especialização de seus dirigentes, podem se beneficiar do apoio e estímulos oferecidos por órgãos externos, sejam eles ligados ao governo ou a entidades setoriais, para aprimorar as práticas de gestão aplicada, incrementando rotinas organizacionais. MPE que receberam o suporte de programas promovidos por entidades externas apresentaram um melhor desempenho quando comparadas com empresas que não participaram de programas, evidenciado que o apoio externo é um recurso útil para aumentar ganhos através do desenvolvimento e capacitação de proprietários-dirigentes e equipes de colaboradores (SARDER et al., 1997).

É neste ponto que emerge o foco de interesse deste estudo: a atuação do SEBRAE no sentido de estimular a criação de políticas e práticas de GRH nas MPE. Sendo assim, o presente trabalho é norteado por duas perguntas: Como o SEBRAE oferece direcionamentos relacionados ao desenvolvimento de políticas e práticas de GRH em MPE e sobre quais aspectos de políticas e práticas de GRH recaem esses direcionamentos. Para responder essas perguntas conduzimos pesquisas nos materiais disponibilizados online pelo SEBRAE em seu portal nacional e em seus portais regionais e conduzimos entrevistas com um consultor no escritório regional de São Paulo e uma consultora do Rio Grande do Sul.

Cabe destacar que nos levantamentos bibliográficos para este artigo não foram localizadas pesquisas que analisassem a atuação da entidade no sentido de estimular especificamente o desenvolvimento de políticas e práticas de GRH.

O presente artigo é composto dos seguintes capítulos: referencial teórico, onde são abordados autores que desenvolveram pesquisas sobre práticas GRH, práticas de GRH em MPE, pesquisas sobre 
a necessidade de apoio externo para o desenvolvimento de MPE, breve histórico do SEBRAE, métodos de pesquisa, apresentação de dados, análise e discussão dos resultados e considerações finais.

\section{REFERENCIAL TEÓRICO}

Com a finalidade de prover amparo teórico para a pergunta de pesquisa, neste capítulo são apresentados autores que desenvolveram conceitos gerais sobre GRH, assim com autores que pesquisaram as rotinas de GRH em MPE. Na terceira seção, são apresentadas pesquisas que evidenciam a relevância do apoio de entidades externas às MPE para estimular o aprimoramento de práticas de gestão, mostrando impacto positivo para o crescimento dessas organizações.

\subsection{GESTÃO DE RECURSOS HUMANOS}

Boxall e Purcell (2008) definem gestão de recursos humanos como todas as atividades associadas ao gerenciamento do trabalho e das pessoas nas empresas e em outros tipos de organizações. Para os autores, a GRH é um processo que acompanha a expansão das organizações e é consequiência do sucesso empreendedor e do crescimento organizacional. As políticas e práticas relacionadas com a forma de organizar o trabalho incluem sua estrutura fundamental, que reúne funções com maior ou menor grau de autonomia e também qualquer oportunidade para os empregados de envolvimento na solução de problemas e nas mudanças gerenciais abarcadas nos processos de trabalho (BOXALL; PURCELL, 2008).

Já as políticas e práticas referentes ao emprego de pessoas estão relacionadas com a forma como as empresas tentam contratar e gerenciar recursos humanos. Elas incluem atividades de recrutamento, seleção, demissão, motivação, recompensa, treinamento, desenvolvimento e retenção de indivíduos. Abrangem ainda processo de informação, consulta e negociações individuais e em grupos, além de atividades associadas com a disciplina de colaboradores, encerramento de contratos e redução de quadros funcionais (BOXALL; PURCELL, 2008).

Legge (2005) defende que a importância da gestão de recursos humanos não está na realidade objetiva dos modelos normativos e na sua aplicação, mas na realidade fenomenológica de sua retórica. A gestão deveria ser entendida como uma construção cultural, compreendendo várias metáforas que redefinem o significado do trabalho e a relação dos empregados com seu trabalho. Nesse sentido, as abordagens normativas e prescritivas encontram dificuldade de aplicação em ambientes onde a produção em massa não é a tônica dominante. A autora diferencia ainda duas abordagens da GRH que privilegiam distintas configurações: de um lado, a abordagem hard foca no alinhamento dos recursos humanos com a estratégia da organização no sentido de garantir que os objetivos traçados na estratégia sejam alcançados, entendendo as pessoas como um recurso necessário para esse fim. A abordagem soft enxerga os recursos humanos também como fundamentais para a estratégia da organização, porém, está mais interessada na colaboração das pessoas, em seu comprometimento com a organização e com seus valores, vendo-as menos como recursos passivos e mais como processos produtivos (LEGGE, 2005).

Wright e Boswell (2002) apontam que as pesquisas acadêmicas têm se dedicado nos últimos anos a tentar entender como os sistemas de recursos humanos podem ajudar no alcance dos objetivos estratégicos das organizações. Os autores indicam o estudo realizado por Huselid em 1995, estabelecendo relação entre as práticas de RH e o desempenho financeiro das organizações, como um texto seminal e o mais citado nesta área. Wright e Boswell (2002) estabelecem ainda uma distinção entre políticas e práticas de RH. Para eles, as políticas representam a intenção estabelecida pela firma sobre 
os tipos de programas, processos e técnicas de GRH que deveriam ser aplicadas na organização. Já as práticas, segundo eles, consistem dos próprios programas, processos e técnicas que serão efetivamente operacionalizados na organização.

Wright (1998) defende ainda um "encaixe horizontal" (horizontal fit) para as práticas de GRH nas organizações. Para ele o encaixe perfeito seria aquele que acontece quando todas as práticas promovem o mesmo resultado para a organização. Em uma empresa que procura concorrer através do bom serviço ao cliente, por exemplo, esse encaixe horizontal acontece quando o sistema de recrutamento e seleção atraem pessoas com alto nível de habilidade e atitude no atendimento ao cliente; em que o sistema de compensação premia aqueles que oferecem melhor atenção ao cliente e o sistema de treinamento se preocupa em treinar os colaboradores para um atendimento eficiente. Para Wright (1998), os modelos atuais de gestão por competências oferecem um quadro de referência para a criação deste encaixe horizontal.

Nesse contexto, faz sentido afirmar que as práticas de GRH influenciam para o crescimento e desenvolvimento de uma organização de grande porte. Contudo, é necessário compreender as especificidades de sua aplicação em MPE, como será verificado abaixo.

\subsection{GESTÃO DE RECURSOS HUMANOS EM MICRO E PEQUENAS EMPRESAS}

No final dos anos 1990, um maior número de artigos sobre o tema da GRH em ambientes de MPE passou a ser publicado em vários periódicos acadêmicos (WILKINSON, 1999; DUNDON et al., 1999; HENEMAN et al., 2000; BARRET; RAINNIE, 2002; MAZZAROL, 2003; CARDON; STEVENS, 2004). Um dos textos fundamentais nesse período é o de Wilkinson (1999) apontando que não há um tipo único de MPE, sendo por isso difícil generalizar sobre as relações de trabalho nesses ambientes. A dicotomia entre o "pequeno bonito" (small is beautiful) e o "buraco negro" (black hole) nas MPE foi retomando nesse período por Dundon et al. (1999), que se preocuparam em avaliar o nível de envolvimento sindical dos trabalhadores desses empreendimentos e apontaram que a ideologia da "cultura familiar" encontrado nas pequenas empresas é uma barreira significativa para a sindicalização dos trabalhadores. Esses autores consideraram que a expressão "buraco negro" se adéqua melhor às características da exploração de mão de obra que podem ocorrer nesses ambientes.

Heneman et al. (2000) conduziram uma investigação qualitativa para identificar a lacuna entre os temas que interessam aos gestores de MPE em crescimento e aqueles enfatizados pela literatura de GRH em MPE. No estudo, descobriram que recrutamento e compensação são os dois assuntos mais abordados na literatura, mas a forma como o tema do recrutamento tem sido explorada na produção acadêmica ainda não atende plenamente a demanda dos gestores. Os autores apontaram a pouca sistematização de dados oficiais, a falta de tempo dos gestores para atender aos pesquisadores e a baixa aceitação do tema em publicações de maior respaldo acadêmico como entraves para um aprofundamento do tema na literatura (HENEMAN et al., 2000).

Na Austrália, a academia tem dado considerável atenção às MPE. De lá vem a produção de Barrett e Rainnie (2002), que defenderam a necessidade de uma abordagem integrada para análise das relações de trabalho em MPE. Mazzarol (2003) investigou a natureza da GRH em MPE que experimentam crescimento, observando que a necessidade de formalização de políticas de RH aumenta com o crescimento da empresa. O estudo de caso múltiplos realizado pelo autor registrou que, na visão dos proprietários-dirigentes, recrutar, motivar e reter bons colaboradores é um gargalo crítico no crescimento do negócio. A falta de habilidade dos proprietários-dirigentes para articular e comunicar 
sua visão do negócio aos empregados, segundo o estudo, cria um distanciamento da estratégia e de sua operacionalização (MAZZAROL, 2003).

Cardon e Stevens (2004) fizeram um dos poucos estudos americanos sobre o assunto nesse período. Adotando uma abordagem funcional e partindo da revisão da literatura englobando 37 artigos sobre GRH em MPE, os autores confirmaram o que já havia sido apontado por Heneman et al. (2000): recrutamento e compensação são os dois temas mais abordados na literatura sobre GRH nas pequenas empresas. Eles se preocuparam também em diferenciar a empresa nova da MPE. Vários empreendimentos nascem pequenos, mas entendem essa dimensão apenas como uma etapa num projeto de crescimento, enquanto outras nascem e permanecem pequenas por necessidade do próprio tipo de negócio. A literatura não tem diferenciado essas naturezas e vários estudos que abordam a pequena empresa o fazem, na verdade, a partir do estudo de startups que objetivam o crescimento e a transformação em empreendimentos maiores.

É possível apontar, através do que foi publicado até aqui na literatura sobre MPE, que as práticas de GRH nesse tipo de organização, quando comparadas a organizações de grande porte, podem ser consideradas incipientes (WILKINSON, 1999), pouca formalizadas (HENEMAN et al., 2000) e sem alinhamento com a estratégia organizacional (MAZZAROL, 2003).

\subsection{NECESSIDADE DE SUPORTE EXTERNO PARA O CRESCIMENTO DAS MICRO E PEQUENAS EMPRESAS}

Como destaca Wilkinson (1999), em termos gerais, as MPE sofrem com a escassez de recursos e a falta de especialização técnica e gerencial de seus dirigentes. No tocante à GRH, isso prejudica o crescimento da empresa. Também a questão da escassez de recursos e do baixo nível de especialização dos integrantes das MPE impacta na perda de competitividade e em dificuldades para a conquista de novos mercados. Diante dessas adversidades intrínsecas, considerando que estas organizações possuem grande relevância para o desenvolvimento social por representarem uma alternativa para geração de empregos e aumento de renda, Mambula (2002) sugere a adoção de programas de suporte que auxiliem no desenvolvimento e crescimento desse tipo de empreendimento. Para Mambula (2002), parcerias entre órgãos governamentais e associações setoriais podem contribuir no sentido de aumentar as redes de relações nas quais as MPE atuam, aumentando o conhecimento e gerando processos de aprendizagem organizacional, iniciados através da capacitação de proprietários-dirigentes.

Jutla et al. (2002) pesquisaram o impacto de iniciativas governamentais para o desenvolvimento e inserção das MPE no contexto do comércio virtual. Para os autores, as iniciativas governamentais estimulam empresas a desenvolverem estratégias e a colherem ganhos de desempenho. Eles concluem que as ações são positivas para o desenvolvimento das MPE. Sarder et al. (1997) estudaram o desempenho de MPE que receberam o suporte de serviços de programas governamentais direcionados para a profissionalização das rotinas organizacionais, comparando-os com MPE que não receberam o mesmo suporte. Os autores constataram que as empresas que receberam o apoio obtiveram maiores ganhos financeiros quando comparadas com as empresas que não o receberam.

Assim, é possível verificar que o desenvolvimento de políticas e práticas de gestão nas MPE pode ser positivamente influenciado pelo suporte de órgãos externos e é neste ponto que emerge a atuação do SEBRAE enquanto entidade de apoio, conforme se verá abaixo. 


\subsection{SERVIÇO BRASILEIRO DE APOIO ÀS MICRO E PEQUENAS EMPRESAS (SEBRAE)}

O SEBRAE foi criado em 1972 como uma entidade privada sem fins lucrativos. Sua missão é promover a competitividade e desenvolvimento sustentável de empresas de micro e pequeno porte. A entidade atua também no sentido de fortalecer o empreendedorismo através do assessoramento nos processos de formalização de empreendedores em situação não regular perante órgãos que administram a economia formal (SEBRAE, 2011a).

A atuação do serviço é pública, ao contribuir para a transformação e expansão de pequenos empreendimentos, contribuindo para o desenvolvimento nacional através da geração de empregos e o conseqüente aumento de renda. A amplitude de sua atuação é nacional, com escritórios nos 27 estados da federação. O SEBRAE possui ainda uma série de acordos e programas desenvolvidos em parceria com órgãos da administração pública ligados ao governo federal e aos governos dos estados e municípios, além de programas desenvolvidos em parceria com órgãos setoriais da iniciativa privada de diversos setores da economia, como agronegócio, tecnologia, vestuário e calçados. A finalidade dessas parcerias é promover ações para cumprir a missão da entidade, possibilitando o desenvolvimento de programas que auxiliem empresas do setor no qual atua (SEBRAE, 2011a).

Um exemplo deste tipo de ação é o programa "Fruta Paulista" que o SEBRAE desenvolve no estado de São Paulo em parceria com o Instituto Brasileiro de Frutas - IBRAF. O programa tem por finalidade melhorar a qualidade da produção de frutas, através da implementação de técnicas e práticas constantes nas chamadas "Boas Práticas Agrícolas". Para tanto, o IBRAF desenvolveu cartilhas explicativas e oferece técnicos especializados para dar consultorias aos fruticultores, enquanto o SEBRAE atua no sentido de disseminar o conteúdo das cartilhas, além de financiar viagens dos técnicos especializados por todo o estado (CAMPOS, 2010).

Nas pesquisas bibliográficas realizadas para a elaboração do presente trabalho, foi possível localizar estudos sobre a atuação do SEBRAE dentro dos seguintes temas: (a) Desenvolvimento regional (RIBEIRO et al., 2002); (b) Percepção dos usuários sobre as contribuições dos programas de desenvolvimento de empresas promovidos pelo SEBRAE (OLIVEIRA; GUIMARÃES, 2003); (c) Agronegócio (OLIVEIRA, 2006); (d) Gestão ambiental (SANTIAGO; DEMAJOROVIC, 2010), e (e) Internacionalização de micro e pequenas empresas (CAMPOS et al., 2011).

A diversidade de temas reflete os diferentes campos em que o SEBRAE atua no contexto da gestão de MPE. Contudo, não foram localizadas pesquisas sobre a atuação da entidade no desenvolvimento de políticas e práticas de GRH.

\section{MÉTODO DE PESQUISA}

A presente pesquisa tem por objetivo investigar os direcionamentos oferecidos pelo SEBRAE para o desenvolvimento de políticas e práticas de GRH, com especial interesse em saber sobre quais aspectos de políticas e práticas de GRH recaem esses direcionamentos. Trata-se, portanto, de um estudo exploratório voltado para o levantamento de informações sobre o fenômeno estudado (SELLTIZ et al., 2004).

Para realizar uma descrição rica e fundamentada foi adota a metodologia qualitativa, que permite o levantamento de uma gama de informações sobre uma pequena amostragem (VIEIRA, 2005). Creswell (1998) explica que estudos qualitativos possuem cinco tradições de pesquisa - pesquisa biográfica, pesquisa fenomenológica, teorização embasada, pesquisa etnográfica e estudo de caso - no presente estudo optou-se pela última tradição. 
De acordo com Stake (1994), o estudo de caso é oportuno em pesquisas cujo objeto de estudo é uma pessoa, um programa, uma instituição, uma empresa ou determinado grupo de pessoas. Quanto ao estudo de caso único, Yin (2001) explica que é aplicável em situações nas quais há características de raridade. Nesta pesquisa a instituição estudada é o SEBRAE, que apresenta características singulares que justificam o estudo de caso único, não havendo nenhuma outra entidade no cenário nacional com características semelhantes - atuação em âmbito nacional com a missão de estimular e desenvolver ações empreendedoras de micro e pequenas organizações.

Quanto às fontes de dados (YIN, 2001), estes foram obtidas por meio de entrevistas semiestruturadas, cujas perguntas foram elaboradas com base nos conceitos sobre políticas e práticas de GRH discutidos nas seções 2.1 e 2.2, conforme Quadro 1.

Quadro 1 - Roteiro de entrevista semiestruturada

\begin{tabular}{|c|c|c|}
\hline Conceito & Autor & Pergunta \\
\hline Políticas e práticas de RH. & Boxall e Purcell (2008) & $\begin{array}{l}\text { Quais são as recomendações do } \\
\text { SEBRAE para o desenvolvimento } \\
\text { políticas e práticas de GRH? }\end{array}$ \\
\hline Alinhamento estratégico da GRH & $\begin{array}{l}\text { Legge (2005); Wright e Boswell } \\
\text { (2002). }\end{array}$ & $\begin{array}{l}\text { Qual é o entendimento do SEBRAE } \\
\text { sobre a questão do alinhamento entre a } \\
\text { GRH com as estratégias da empresa? }\end{array}$ \\
\hline Práticas de GRH. & Boxall e Purcell (2008) & $\begin{array}{l}\text { Quais são as recomendações do } \\
\text { SEBRAE sobre recrutamento, seleção, } \\
\text { demissão, motivação, recompensa, } \\
\text { treinamento, desenvolvimento e } \\
\text { retenção de funcionários? }\end{array}$ \\
\hline Gestão por competências & Wright (1998) & $\begin{array}{l}\text { Quais são os direcionamentos SEBRAE } \\
\text { sobre o perfil de competências } \\
\text { específicas no momento de realizar } \\
\text { contratação de pessoal? }\end{array}$ \\
\hline "Pequeno bonito" & Wilkinson (1999) & $\begin{array}{l}\text { Qual é a percepção do SEBRAE sobre o } \\
\text { ambiente organizacional no tocante à } \\
\text { GRH? Existiram casos de ambientes } \\
\text { familiares e flexíveis? }\end{array}$ \\
\hline "Buraco negro" & Wilkinson (1999) & $\begin{array}{l}\text { Na percepção do SEBRAE há empresas } \\
\text { com ambiente nebuloso, com baixas } \\
\text { garantias em termos dos direitos } \\
\text { laborais que envolvem a GRH? Em caso } \\
\text { afirmativo, em quais circunstâncias } \\
\text { emergem esses ambientes? }\end{array}$ \\
\hline $\begin{array}{l}\text { Baixo nível de especialização } \\
\text { sobre GRH. }\end{array}$ & Mazzarol (2003) & $\begin{array}{l}\text { Como os empreendedores exercem as } \\
\text { práticas de recrutar, motivar e reter } \\
\text { colaboradores? }\end{array}$ \\
\hline
\end{tabular}

Fonte: Elaborado pelos autores

As entrevistas foram realizadas com dois consultores do SEBRAE em São Paulo e uma instrutora de Porto Alegre. Os entrevistados de São Paulo eram analistas pleno e sênior, com cinco e oito anos de atuação na Instituição respectivamente. A instrutora possuía quatro anos de atuação. As entrevistas, com cerca de uma hora de duração cada uma, foram gravadas em áudio. A escolha dessas duas capitais para as entrevistas foi motivada pelo fato de que o estado de São Paulo, juntamente com o Rio Grande do Sul, são os que possuem maior quantidade de escritórios da entidade na região sudeste e sul, respectivamente, de acordo com o Quadro 2. Por isso, a atuação do SEBRAE nestes estados é considerada de maior abrangência, atingindo maior número de empresas, quando comparada com a atuação nos demais estados de cada região. 
Quadro 2 - Número de escritórios regionais por estado

\begin{tabular}{|l|c|l|c|}
\hline Sudeste & Número de escritórios & Sul & Número de escritórios \\
\hline Espírito Santo & 11 & Paraná & 17 \\
\hline Minas Gerais & 50 & Rio Grande do Sul & 36 \\
\hline Rio de Janeiro & 43 & Santa Catarina & 16 \\
\hline São Paulo & 123 & \multicolumn{2}{|}{} \\
\cline { 1 - 3 } & &
\end{tabular}

Fonte: Elaborado com base em informações do site do SEBRAE

Seguindo as orientações de Yin (2001), as informações foram trianguladas com análise documental de informações extraídas do portal virtual regional do SEBRAE na internet em cada um dos estados (SEBRAE, 2011b; SEBRAE; 2011c) e com brochuras em formato PDF constantes na biblioteca virtual do SEBRAE (SEBRAE, 2011a).

Quanto à análise desses dados, foi utilizada a técnica de análise de conteúdo. Segundo Bardin (1977), a análise de conteúdo constitui-se em um conjunto de técnicas que possibilitam inferir conhecimentos relacionados às condições de produção e recepção de mensagens, possibilitando ao pesquisador verificar o conteúdo explícito (objetivo) juntamente com interpretação de aspectos implícitos (subjetivo) do texto. Dessa forma, os conceitos teóricos discutidos no capítulo 2 serviram como base para o desenvolvimento de categorias que instrumentalizaram as análises.

\section{DADOS}

\subsection{DADOS COLHIDOS NO SEBRAE NO RIO GRANDE DO SUL}

Os dados coletados nas entrevistas no SEBRAE-RS apontam uma atuação ainda incipiente da instituição nas questões ligadas à GRH. Embora exista a consciência de que o capital humano é um recurso fundamental no desenvolvimento de qualquer empreendimento, admite-se que a entidade ainda está num estágio muito inicial de orientação aos empresários quanto às políticas e práticas de GRH. De acordo com o entrevistado, há "uma certa resistência" por parte dos proprietários-dirigentes para receberem treinamento de aspectos básicos do negócio, como controle de fluxo de caixa e planejamento financeiro, considerando os aspectos de GRH uma sofisticação ainda distante para eles. Por outro lado, há uma preocupação por parte do SEBRAE em direcionar esforços para uma ampliação da atuação da entidade em relação a esse tema, tanto na sua grade de cursos, como na elaboração de material didático e outros instrumentos instrucionais. Como é possível verificar na seguinte passagem da entrevista:

As pessoas são o grande diferencial de uma empresa. Muitos problemas podem ser resolvidos com dinheiro, você quer melhorar seu produto ou serviço, investe em tecnologia, você quer melhorar seu ambiente de trabalho, investe em reforma. Mas problemas ligados à gestão de pessoas não dá para resolver com dinheiro.

A baixa oferta de cursos ligados às práticas de GRH é verificável na oferta do portal virtual do SEBRAE no Rio Grande do Sul. Foi possível localizar um curso sobre Gestão de pessoas para o comércio varejista, que tem por objetivo "capacitar proprietários-dirigentes para atuar como um líder e proporcionar um ambiente de trabalho saudável visando atrair e manter profissionais competentes para o negócio". Também há um curso sobre Desenvolvimento de equipes cuja finalidade é "apresentar itens considerados como essenciais para o desenvolvimento de uma equipe como confiança, comunicação e compartilhamento de funções".

No estágio atual, o entrevistado acredita que apenas $5 \%$ do treinamento oferecido pela instituição aborda questões de GRH. Há uma percepção de que políticas e práticas de GRH são complexas e, talvez 
por isso, sejam pouco tratadas. Também na gestão interna da própria entidade, reconhece o entrevistado. "há deficiências" quanto à GRH, sofrendo de uma burocratização nos processos e um distanciamento da equipe dos objetivos finais do sistema. No que se refere ao funcionamento das organizações, ele aponta a proximidade de colaboradores e proprietários-dirigentes que operam os empreendimentos como fator que garante a sobrevivência das mesmas. Ainda que o perfil multitarefa esteja fortemente presente, os índices de comprometimento dos colaboradores são bastante altos. Mesmo assim, a falta de treinamento e de preparação para tarefas específicas compromete o futuro das organizações.

Também de acordo com o entrevistado, a taxa de mortalidade nos dois primeiros anos no segmento está em cerca de $22 \%$, tendo já atingido níveis de mais de $50 \%$ no passado. Essa queda se deve mais à estabilidade financeira e, com isso, ao aumento da margem de manobra dos proprietáriosdirigentes quanto aos erros em aspectos fundamentais como o controle de estoques, que necessariamente a uma melhora na gestão geral dos negócios.

\subsection{DADOS COLHIDOS NO SEBRAE DE SÃO PAULO}

$\mathrm{Na}$ entrevista realizada com uma consultora do SEBRAE em São Paulo foi possível verificar que a questão da administração de recursos humanos é incipiente, sendo que os direcionamentos efetuados pelo SEBRAE sobre a questão encontram-se atrelados a outros aspectos do negócio. Por exemplo, no aspecto legal, a fim de evitar problemas de natureza trabalhista, o SEBRAE procura orientar o proprietário-dirigente sobre qual o sindicato que seus colaboradores devem ser filiados. Isto porque é comum casos de proprietários-dirigentes não darem a devida atenção à questão e depois sofrerem reclamações trabalhistas. A questão sindical também se reflete nas práticas de remuneração, uma vez que a orientação que o SEBRAE fornece neste âmbito é de que a empresa remunere seu colaborador com base no piso da categoria.

Segundo a entrevistada, em termos gerais, as práticas de GRH encontram-se inseridas nas diretrizes do plano de negócios, instrumento considerado como uma "ferramenta norteadora" das decisões a serem tomadas pelo empreendedor, criando-se uma lógica de coerência entre a estratégia e a ação.

Um desafio comum enfrentado pelos consultores refere-se ao paradoxo entre empresa "familiar" e empresa "domiciliar". Esta terminologia foi sugerida pela própria consultora entrevistada, com base na experiência cotidiana. As empresas familiares são organizações que possuem certo nível de profissionalização, havendo algumas práticas de GRH, como capacitação técnica de recursos humanos, ainda que estes sejam membros da família do proprietário-dirigente. Nesses ambientes mantém-se algum profissionalismo e há abertura para inovação organizacional proporcional a qualificação de seus recursos humanos, como é possível verificar na seguinte passagem da entrevista: "Na empresa familiar, não se tem visão de inovação, a impressão que temos é que o empresário pensa da seguinte forma, 'Sempre funcionei assim e vou morrer assim'. Este empresário não está preocupado em melhorar sua empresa nem a gestão de pessoas."

A entrevistada citou o exemplo da abertura de uma pizzaria, na qual o proprietário-dirigente terá de contratar pessoas que possuem capacidade para fazer pizzas. No caso de uma empresa "familiar" haverá a preocupação em desenvolver habilidades de recrutamento e seleção para contratar profissionais com a especialização necessária para a função. É pensado ainda políticas de benefícios para atrair e manter estes colaboradores, uma vez que as organizações de pequeno porte têm enfrentado dificuldades para recrutar e manter mão de obra qualificada. 
$\mathrm{Na}$ empresa do tipo "domiciliar", a total ausência de práticas de GRH faz com que os colaboradores sejam selecionados com base apenas na conveniência e confiança pessoal. Assim, há um baixo nível de profissionalismo, juntamente com uma postura de resistência à inovação, pois o proprietário-dirigente não apresenta visão de mudança e inovação organizacional, refletidas em perdas de desempenho organizacional.

No tocante, aos cursos e palestras promovidos pelo SEBRAE paulista, é possível identificar aspectos ligados às práticas de GRH nos temas identificados no Quadro 3.

Quadro 3 - Palestras e cursos promovidos pelo SEBRAE paulista

\begin{tabular}{|l|l|}
\hline Tema & Objetivo \\
\hline 1. Motivando sua empresa para o sucesso & $\begin{array}{l}\text { Sensibilizar o proprietário-dirigente sobre a importância de } \\
\text { manter um bom relacionamento e integração com os } \\
\text { colaboradores. }\end{array}$ \\
\hline 2. Recrutamento e seleção & São ensinadas técnicas de recrutamento e seleção de pessoas. \\
\hline 3. Como evitar reclamações trabalhistas & Orientar sobre espécies de contrato de trabalho e terceirização. \\
\hline 4. Equipe motivada & $\begin{array}{l}\text { Sensibilizar o proprietário-dirigente sobre o benefício do } \\
\text { desenvolvimento constante das equipes e fortalecimento das redes } \\
\text { de relação interna. }\end{array}$ \\
\hline 5. Liderar seu negócio é fundamental & $\begin{array}{l}\text { Orientar os empresários para a importância do papel da liderança } \\
\text { e a sua relação com os seus liderados. Reconhecer que uma } \\
\text { empresa de sucesso necessariamente deve ser composta por uma } \\
\text { equipe vencedora }\end{array}$ \\
\hline
\end{tabular}

Fonte: Adaptado pelos autores a partir de informações do portal virtual do SEBRAE-SP

\subsection{DADOS COLHIDOS NO PORTAL NACIONAL DO SEBRAE NA INTERNET}

Localizaram-se no portal virtual nacional da entidade apostilas identificadas como Instrumentos de Apoio Gerencial em formato PDF. Essas apostilas propõem roteiros de ação sobre itens relacionados ao desenvolvimento de políticas e práticas de GRH. Além dos roteiros, há também questionários denominados "ferramentas" que auxiliam no desenvolvimento e aplicação do item trabalhado.

Foram também encontrados no portal modelos de questionários para pesquisa de clima organizacional, recrutamento e seleção, levantamento de necessidades de capacitação, desenvolvimento de políticas de manutenção, habilidades de vendas, juntamente com orientações sobre motivação de equipe e práticas de reconhecimento. Em termos gerais, as apostilas têm por objetivo conscientizar proprietários-dirigentes a cerca da importância da implementação desses modelos, destacando os benefícios proporcionados para melhoria da empresa.

Os textos são escritos de forma objetiva e clara e no Quadro 4 há uma relação completa das apostilas.

Quadro 4 - Relação dos Instrumentos de Apoio Gerencial na biblioteca virtual do SEBRAE nacional

\begin{tabular}{|l|l|}
\hline Tema & Finalidade \\
\hline $\begin{array}{l}\text { 1. A importância do recrutamento e } \\
\text { seleção para o futuro da empresa }\end{array}$ & $\begin{array}{l}\text { Orientar o propritário-dirigente no sentido de estabelecer critérios de } \\
\text { recrutamento e seleção com vistas a atender as necessidades de sua empresa. }\end{array}$ \\
\hline 2. Capacitação dos colaboradores & $\begin{array}{l}\text { Explicar ao proprietário-dirigente como proceder para manter equipes } \\
\text { qualificadas, evidenciando as vantagens da capacitação dos colaboradores } \\
\text { para o desempenho global de sua empresa. }\end{array}$ \\
\hline $\begin{array}{l}\text { 3. A importância do clima } \\
\text { organizacional em sua empresa }\end{array}$ & $\begin{array}{l}\text { Conscientizar o proprietário-dirigente acerca da relevância em manter um } \\
\text { clima organizacional positivo dentro de sua empresa. }\end{array}$ \\
\hline $\begin{array}{l}\text { 4. Administrar o processo de } \\
\text { manutenção da infraestrutura da } \\
\text { empresa. }\end{array}$ & $\begin{array}{l}\text { Proporcionar ao proprietário-dirigente subsídios para viabilizar a } \\
\text { implementação de processos de gestão da infra-estrutura organizacional } \\
\text { integrando fornecedores, clientes, colaboradores, maquinário, estoque e } \\
\text { demais elementos componentes da estrutura da empresa. }\end{array}$ \\
\hline
\end{tabular}




\begin{tabular}{|l|l|}
\hline Tema & Finalidade \\
\hline 5. Manter a motivação da equipe & $\begin{array}{l}\text { Municiar o proprietário-dirigente com informações sobre comportamento } \\
\text { gerencial e seu impacto para manutenção de um clima organizacional } \\
\text { positivo. }\end{array}$ \\
\hline $\begin{array}{l}\text { 6. Reconhecendo o desempenho dos } \\
\text { colaboradores }\end{array}$ & $\begin{array}{l}\text { Orientar o propritário-dirigente no sentido de desenvolver açães de } \\
\text { reconhecimento do desempenho de colaboradores com base em uma política } \\
\text { de cargos e salários. }\end{array}$ \\
\hline $\begin{array}{l}\text { 7. Desenvolver políticas de cargos e } \\
\text { salários }\end{array}$ & $\begin{array}{l}\text { Sensibilizar o proprietário-dirigente para a necessidade de desenvolver uma } \\
\text { política de cargos e salários que permita definir adequadamente a justa } \\
\text { remuneração de colaboradores, com base na função exercida. }\end{array}$ \\
\hline $\begin{array}{l}\text { 8. Influência sobre a regularização } \\
\text { sindical e trabalhista para o } \\
\text { reconhecimento do colaborador }\end{array}$ & $\begin{array}{l}\text { Sensibilizar o proprietário-dirigente sobre a importância da regularização } \\
\text { sindical e trabalhista para o fortalecimento da relação de trabalho via } \\
\text { manutenção de garantais laborais básicas, com sua equipe de colaboradores. }\end{array}$ \\
\hline $\begin{array}{l}\text { 9. Treinamento adequado } \\
\text { Conscientizar o proprietário-dirigente para a relevância estratégica da adoção } \\
\text { de treinamentos para equipe de colaboradores, objetivando evitar perdas de } \\
\text { desempenho quando são adotadas novas práticas de trabalho na rotina } \\
\text { organizacional. }\end{array}$ \\
\hline $\begin{array}{l}\text { 10. Reconhecer e valorizar } \\
\text { colaboradores através de políticas de } \\
\text { capacitação }\end{array}$ & $\begin{array}{l}\text { Apresentar ao proprietário-dirigente meios para transformar a prática da } \\
\text { capacitação de pessoal em um elemento de reconhecimento e valorização. }\end{array}$ \\
\hline
\end{tabular}

Fonte: Adaptado pelos autores a partir de informações do portal virtual do SEBRAE-Nacional

\subsection{ANÁLISE COMPARATIVA SOBRE AS ORIENTAÇÕES DO SEBRAE}

A análise comparativa entre as orientações sobre RGH do SEBRAE no Rio Grande do Sul e em São Paulo, juntamente com os dados encontrados nas apostilas disponíveis no portal virtual do SEBRAE nacional está sintetizada no Quadro 5.

Quadro 5 - Análise comparativa

\begin{tabular}{|c|c|c|c|}
\hline $\begin{array}{c}\text { Fonte de } \\
\text { Evidência } \\
\end{array}$ & SEBRAE - Rio Grande do Sul & SEBRAE - São Paulo & SEBRAE - Nacional \\
\hline Entrevista & $\begin{array}{l}\text { - As orientações sobre práticas de } \\
\text { GRH ainda são incipientes. } \\
\text { - O capital humano é fundamental } \\
\text { para o desenvolvimento do negócio. } \\
\text { - Há resistências por parte dos } \\
\text { proprietários dirigentes em adotar } \\
\text { práticas de GRH. } \\
\text { - Baixo nível de especialização de } \\
\text { proprietários-dirigentes e equipes de } \\
\text { colaboradores. } \\
\text { - Os colaboradores trabalham dentro } \\
\text { da perspectiva multitarefa e } \\
\text { apresentam bom nível de } \\
\text { comprometimento. }\end{array}$ & $\begin{array}{l}\text { - As orientações sobre práticas de } \\
\text { GRH ainda são incipientes. } \\
\text { - O piso salarial estabelecido em } \\
\text { convenções coletivas serve para } \\
\text { práticas de remuneração. } \\
\text { - O plano de negócios estabelece } \\
\text { diretrizes sobre a qualificação do } \\
\text { profissional a ser contratado. } \\
\text { - Empresas denominadas } \\
\text { 'domiciliar' apresentam baixo } \\
\text { nível de profissionalização em } \\
\text { termos de práticas de GRH. }\end{array}$ & - Nada consta. \\
\hline $\begin{array}{l}\text { Cursos, } \\
\text { palestras e } \\
\text { apostilas }\end{array}$ & $\begin{array}{l}\text { - Gestão de pessoas para o comércio } \\
\text { varejista. } \\
\text { - Desenvolvimento de equipes. }\end{array}$ & $\begin{array}{l}\text { - Motivando sua empresa para o } \\
\text { sucesso. } \\
\text { - Recrutamento e seleção. } \\
\text { - Como evitar reclamações } \\
\text { trabalhistas. } \\
\text { - Equipe motivada. } \\
\text { - Liderar seu negócio é } \\
\text { fundamental. }\end{array}$ & $\begin{array}{l}\text { - Recrutamento e seleção. } \\
\text { - Capacitação. } \\
\text { - Clima organizacional. } \\
\text { - GRH na infraestrutura da } \\
\text { empresa. } \\
\text { - Motivação e } \\
\text { reconhecimento. } \\
\text { - Política de cargos e } \\
\text { salários. } \\
\text { - Regularização sindical. } \\
\text { - Treinamento, } \\
\text { reconhecimento e } \\
\text { valorização. }\end{array}$ \\
\hline
\end{tabular}




\section{ANÁLISE E DISCUSSÃO DOS RESULTADOS}

A partir da análise da tabela 5, é possível verificar que o SEBRAE oferece direcionamentos e ferramentas para o desenvolvimento de práticas e não de políticas de GRH em MPE. Foi possível localizar direcionamentos oriundos de cursos presenciais e de maneira um pouco mais incipiente, nas consultorias realizadas por seus funcionários.

Considerando o conceito de políticas de GRH de Wright e Boswell (2002) como intenções estabelecidas pela organização que servem como pilar para o desenvolvimento de programas, processos e aplicação de técnicas, como um elemento profundo que norteará decisões e ações, demandando reflexão e tomada de decisão por parte de proprietários-dirigentes, percebe-se que nas orientações do SEBRAE não há elementos que caracterizem esse nível de profundidade.

Para o SEBRAE o documento que deve nortear o direcionamento da organização é o plano de negócios, contudo, não é possível afirmar que a partir do plano de negócio serão desencadeadas políticas que refletirão sobre as práticas de GRH. A orientação do SEBRAE sobre práticas de GRH baseadas no plano de negócio remetem a abordagem hard destacada por Legge (2005), já que o plano de negócios traz direcionamentos normativos que limitam o envolvimento e a construção coletiva.

Quanto às práticas propriamente ditas, o SEBRAE traz orientações sobre recrutamento, seleção, recompensa, treinamento e critérios para cargos e salários que se alinham com as práticas descritas por Boxall e Purcell (2008). É possível afirmar, que, considerando a amplitude da missão que o SEBRAE se propõe, juntamente com a abrangência nacional de sua atuação, é difícil para a entidade desenvolver orientações específicas para as necessidades setoriais das MPE. Portanto, as orientações sobre práticas de GRH da entidade possuem caráter generalista, cabendo aos proprietários-dirigentes moldar estes direcionamentos às suas necessidades e ao contexto do mercado no qual atua. $\mathrm{O}$ único ponto de especificidade localizado nos dados foi o curso promovido pelo SEBRAE gaúcho sobre gestão de pessoas no comércio varejista.

A cultura familiar que proporciona um ambiente agradável, que eleva o nível de comprometimento dos colaboradores, destacado na literatura por Wilkinson (1999), foi identificada no conteúdo das entrevistas. Assim, pode-se afirmar que a realidade nacional da GRH em MPE corrobora a literatura internacional sobre no tema, no sentido de que há MPE brasileiras que realizam a GRH de maneira flexível dentro da perspectiva do "pequeno é bonito". Por outro lado, as características de empresas "buraco negro", com baixo nível de sindicalização, mencionadas por Dundon et al. (1999) não foram suportadas pelos dados.

O baixo nível de especialização do capital humano da MPE, destacado por Wilkinson (1999), foi também atestado pelos entrevistados no contexto brasileiro. Nas duas entrevistas foi mencionado que existem organizações que pecam neste ponto, em especial nas empresas dotadas de características "domiciliares", onde não há direcionamentos para qualificação e capacitação do capital humano.

Também foi apontada nas entrevistas a resistência por parte de proprietários-dirigentes na melhoria da qualificação técnica em geral. Essa resistência gera dificuldades para recrutar e reter colaboradores, conforme destacado na literatura por Mazzarol (2003).

Em relação à importância da atuação de um órgão externo para o desenvolvimento das práticas de gestão em MPE, conforme sugerido nos trabalhos de Sarder et al. (1997), Jutla et al. (2002) e Mambula (2003), não foi possível mensurar o nível de influência e eficácia em termos de implementação de ações práticas dos direcionamentos do SEBRAE nas rotinas de GRH. Considerando, no entanto, o que foi apontado nas entrevistas com membros do SEBRAE, as iniciativas da entidade neste sentido são 
incipientes, sugerindo que a internalização dos direcionamentos de GRH nas rotinas organizacionais deve ser de pouca representatividade.

Em relação à pergunta de pesquisa que norteou o presente trabalho, é possível afirmar que os direcionamentos do SEBRAE para o desenvolvimento do GRH em MPE são voltados para a implementação de práticas previstas pela literatura sobre o tema, mas que a entidades, no entanto, não consegue atingir um nível de profundidade de forma que esses direcionamentos possibilitem a elaboração de políticas. Esta atuação é considerada insuficiente e deveria receber maior atenção da instituição.

\section{CONSIDERAÇÕES FINAIS}

A presente pesquisa teve por objetivo estudar os direcionamentos que o SEBRAE oferece para o desenvolvimento de políticas e práticas de GRH em MPE, focando em verificar sobre quais pontos das políticas e práticas de GRH recaem esses direcionamentos. Foi possível localizar direcionamentos que estimulam a adoção de práticas, como critérios de recrutamento e seleção, treinamento e desenvolvimento, juntamente com critérios para estipular cargos e salários. Contudo, os direcionamentos não possuem um nível de profundidade que possibilitem a criação de políticas de GRH. Tampouco os direcionamentos apresentam características idiossincráticas voltadas para o setor econômico competitivo no qual cada organização atua.

Assim, é possível questionar a eficácia desses direcionamentos em termos de sua internalização nas rotinas organizacionais. Esse quadro é agravado pela resistência que a entidade enfrenta quando se propõe a ministrar novos conhecimentos que auxiliariam proprietários-dirigentes a gerir com maior eficiência e eficácia o seu negócio.

Estudos futuros comparativos entre MPE que profissionalizaram seus processos e MPE com menor nível de profissionalização poderiam contribuir para um maior entendimento da internalização dos direcionamentos sobre políticas e práticas de GRH nas empresas orientadas pelo SEBRAE. Como foi observado nas entrevistas, os próprios membros do SEBRAE acreditam que empresas profissionalizadas apresentam maiores chances de obter resultados melhores quando comparadas com as empresas menos profissionalizadas (SARDER et al., 1997).

Futuras pesquisas poderiam ainda investigar as práticas de GRH nos diversos setores econômicos e oferecer subsídios para que o SEBRAE desenvolva direcionamentos mais específicos, voltados para as reais necessidades setoriais das organizações. Sugere-se, para isso, que sejam aplicados métodos qualitativos para levantamento de informações com profundidade a partir da uma amostra pequena, e que posteriormente estas informações sirvam de base para elaboração de survey com a finalidade de verificar a aderência das informações sobre uma amostra maior de pesquisa.

Cabe ressaltar que a presente pesquisa se limitou ao estudo do SEBRAE no âmbito dos estados do Rio Grande do Sul e de São Paulo, juntamente com informações colhidas no portal virtual nacional da instituição. Sugere-se que a pesquisa seja replicada em outros estados para verificar se os direcionamentos da entidade para políticas e práticas de GRH seguem a mesma lógica.

\section{REFERÊNCIAS}

BARDIN, L. Análise de conteúdo. Lisboa: Edições 70, 1977.

BARRET, R.; RAINNIE, A. What is So Special About Small Firms? Work, Employment and

Society, v.16, n.3, p. 415-431, 2002. 
BREWSTER, C. Managing Industrial Relations. In: TOWERS, B. A Handbook of Industrial Relations Practice. $3^{\mathrm{a}}$ ed. London: Kogan Page Ltd, p.105-122, 1992.

BOXALL, P.; PURCELL, J. Strategy and Human Resource Management. $2^{\text {a. }}$ ed. New York: Palgrave MacMillan, 2008.

CARDONS, M. S.; STEVENS, C. E. Managing Human Resources in Small Organizations: What do we Know? Human Resource Management Review, v.14, p.295-323, 2004.

CAMPOS, T. M. Gestão estratégica voltada para a exportação em MPE fruticultoras. Dissertação de Mestrado. Programa de Mestrado e Doutorado em Administração da Universidade Nove de Julho, São Paulo, 2010.

CAMPOS, T. M.; LIMA, E. O.; URBANAVICIUS, V. Jr.; ALVES, D. V. Internacionalização de micro e pequenas empresas: Um estudo de caso sobre a atuação do SEBRAE. Revista da Micro e Pequena Empresa, v.5, n.1, p.36-50, 2011.

DUNDON, T.; GRUGULIS, I.; WILKINSON, A. Looking out of the black-hole Non-Union Relations in an SME. Employee Relations, v.21, n.3, p.251-266, 1999.

HENEMAN, R. L.; TANSKY, J. W.; CAMP, S. M. HRM Practices in Small and Medium-Sized Enterprises: Unanswered Questions and Future Research Perspectives. Entrepreneurship Theory and Practice, v. 25, n.1, p.11-26, 2000.

SARDER, J. H.; GHOSH, D.; ROSA, P. The importance of support services to small enterprise in Bangladesh. Journal of Small Business Management, v.35, n.2, p.25-36, 1997.

HUSELID, M. A. The Impact of human resource management practices on turnover, productivity and corporate finance performance. Academy of Management Journal, v.38, n.3, p.635-672, 1995.

JUTLA, D.; BODOROVIK P.; DHALIWAL, J. Supporting the e-business readiness of small and medium-sized enterprises: Approaches and metrics. Internet Research, v. 12, n. 2. p. 139-164, 2002.

LEGGE, K. Human resource management: Rhetorics and realities. Anniversary Edition. New York: Palgrave MacMillan, 2005.

MAMBULA, C. Perceptions of SME growth constraints in Nigeria. Journal of Small Business Management, v.40, n.1, p. 58-65, 2002.

MAZZARAOL, T. A Model of Small Business HR. Growth Management, v.9, n.1, p.27-49, 2003.

OLIVEIRA, D. C.; GUIMARÃES, L. O. Perfil Empreendedor e ações de apoio ao empreendedorismo: o NAE/SEBRAE em questão. Anais... XXVII EnANPAD, 2003.

OLIVEIRA, F. M. J. Gestão agroindustrial: Um estudo sobre o modelo "SEBRAE-RN" de produção de mel de abelhas no Rio Grande do Norte. Dissertação de Mestrado. Programa de Engenharia de Produção da Universidade Federal do Rio Grande do Norte, Natal, 2006.

RIBEIRO, C.; MENDONÇA, P; GUEDES, P. Modelos organizacionais para o desenvolvimento local integrado e sustentável: O estudo de caso do SEBRAE/BA. Anais... XXVI EnANPAD, 2002.

SANTIAGO, A. J.; DEMAJOROVIC, J. Desafios e práticas socioambientais na micro e pequena empresa: uma análise das empresas integrantes do programa SEBRAE-SP de gestão ambiental.

Anais... XXXIV EnANPAD, 2010. 
SEBRAE 2011a. Disponível em: <www.sebrae.com.br>. Acesso em: 27 jun. 2011.

SEBRAE 2011b. Disponível em: <www.sebrae-rs.com.br〉. Acesso em: 03 jun. 2011.

SEBRAE 2011c. Disponível em: <www.sebraesp.com.br>. Acesso em: 04 jun. 2011.

SELLTIZ, C., WRIGHSTMAN, L.; COOK, S. Métodos de pesquisa nas relações sociais. 4. ed., v. 1. São Paulo: EPU, 2004.

STAKE, R. Case study. In: DENZIN, N.; LICOLN, Y. Handbook of qualitative research. Thousand Oaks, Califórnia: Sage, 1994.

VIEIRA, M. Por uma boa pesquisa (qualitativa em administração). In: ZOUAIN, D. e VIEIRA M. (Orgs.). Pesquisa qualitativa em administração. São Paulo: Editora FGV, p. 3-28, 2004.

WILKINSON, A. Employment Relations in SME. Employee Relations, v.21, n.3, p.206-217, 1999.

WRIGHT, P. M. Strategy - HR fit: Does it really matter? Human Resource Planning, v.21, n.4, p.56-57, 1998.

WRIGHT, P. M.; BOSWELL, W.R. Desegregating HRM: A Review and synthesis of micro and macro human resource management research. Journal of Management, v. 28, n.3. p.247-276, 2002.

YIN, R. Estudo de caso: planejamento e métodos. 2. ed. Porto Alegre: Bookman, 2001. 